Jose M. Carnate, Jr., MD

Vincent G. Te, MD²

Michelle Anne M. Encinas-Latoy, MD'

'Department of Pathology,

College of Medicine

University of the Philippines Manila

${ }^{2}$ Department of Laboratories,

University of the Philippines Manila

Philippine General Hospital

\section{Middle Ear Paraganglioma}

A 51-year-old woman underwent mastoidectomy with labyrinthectomy on the right for a polypoid external auditory canal mass accompanied by tinnitus and ear discharge. She was reported to have undergone mastoidectomy on the same site seven years prior to the present consult. The material from this prior surgery was not made available to us.

The submitted specimen from this surgery consisted of several dark brown irregular tissue fragments with an aggregate diameter of 4.2 centimeters. Histologic sections show tumor cells arranged in "ball-like" clusters that are surrounded by a network of sinusoidal channels. The cells are round to oval with round, uniform nuclei that have finely granular chromatin and moderate amounts of eosinophilic to amphophilic cytoplasm. (Figure 1) Mitoses, nuclear pleomorphism and hyperchromasia are not observed. Immunohistochemical studies show diffuse cytoplasmic positivity for synaptophysin and chromogranin. (Figure 2) The S100 stain highlights a peripheral layer of cells taking up the stain around the cell clusters. (Figure 3) Based on these features, we diagnosed the case as a paraganglioma likely a recurrence.

Paragangliomas are neuroendocrine neoplasms that arise from paraganglia found in various anatomic locations. ${ }^{1}$ In the middle ear, they arise from paraganglia found in the adventitia of the jugular bulb - hence, the old synonym "glomus jugulare" and "glomus tympanicum." Other sites where they can develop include paraganglia of the carotid artery bifurcation ("chemodectoma"), the larynx and the vagal trunk ("glomus vagale"). The World Health Organization has simplified the nomenclature of these tumors by calling all of them simply "paraganglioma" and specifying the site involved.' In our case, it is likely a middle ear paraganglioma borne out by the history, clinical picture, and the morphology. Head and neck paragangliomas occur in adults from the $5^{\text {th }}$ $-6^{\text {th }}$ decade, more commonly in females, and present mostly with mass-related symptoms. ${ }^{2,3}$

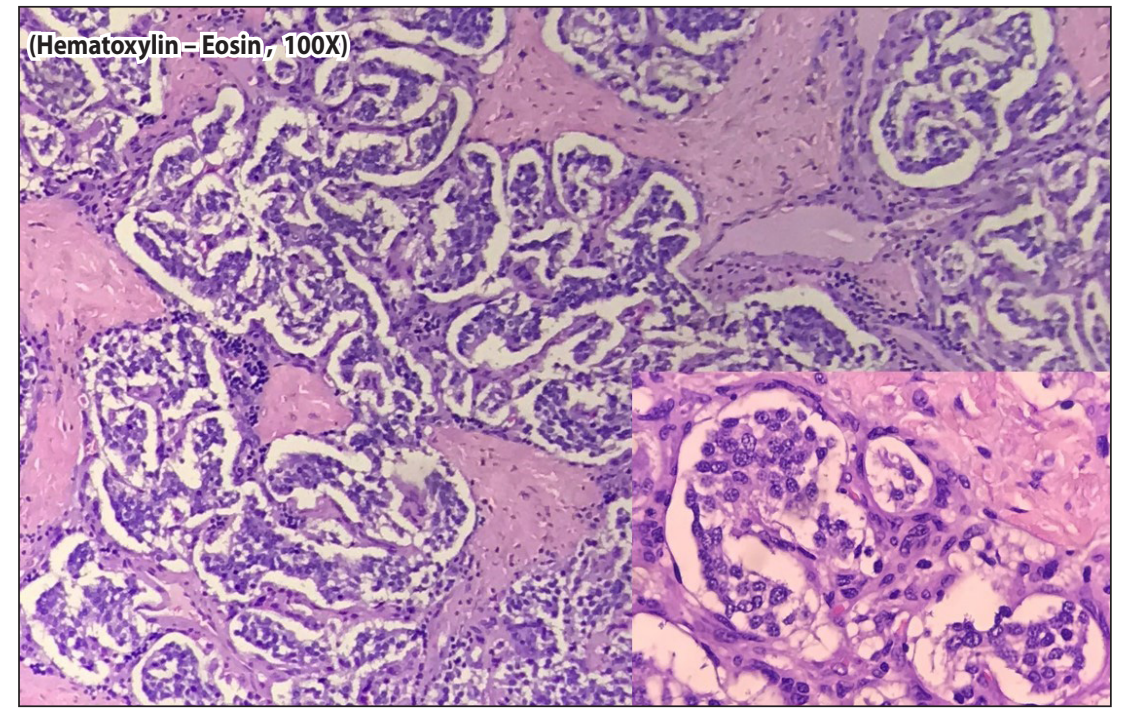

Figure 1. Tumor cells arranged in "ball-like" clusters surrounded by vascular channels (Hematoxylin-eosin, 100X magnification). High power (inset) shows round to oval cells with round uniform nuclei and finely granular chromatin (Hematoxylin-eosin, 400X magnification).
Correspondence: Dr. Jose M. Carnate, Jr. Department of Pathology College of Medicine, University of the Philippines Manila 547 Pedro Gil St. Ermita, Manila 1000 Philippines

Phone (632) 526-4450

Telefax (632) 400-3638

Email:jmcjpath@gmail.com

The authors declared that this represents original material that is not being considered for publication or has not been published or accepted for publication elsewhere, in full or in part, in print or electronic media; that the manuscript has been read and approved by the authors, that the requirements for authorship have been met by the authors, and that the authors believe that the manuscript represents honest work.

Disclosures: The authors signed disclosures that there are no financial or other (including personal) relationships, intellectual passion, political or religious beliefs, and institutional affiliations that might lead to a conflict of interest.

\section{(c) $9 \Theta \Theta$}

Creative Commons (CC BY-NC-ND 4.0)

Attribution - NonCommercial - NoDerivatives 4.0 International
(C) Philippine Society of Otolaryngology - Head and Neck Surgery, Inc 


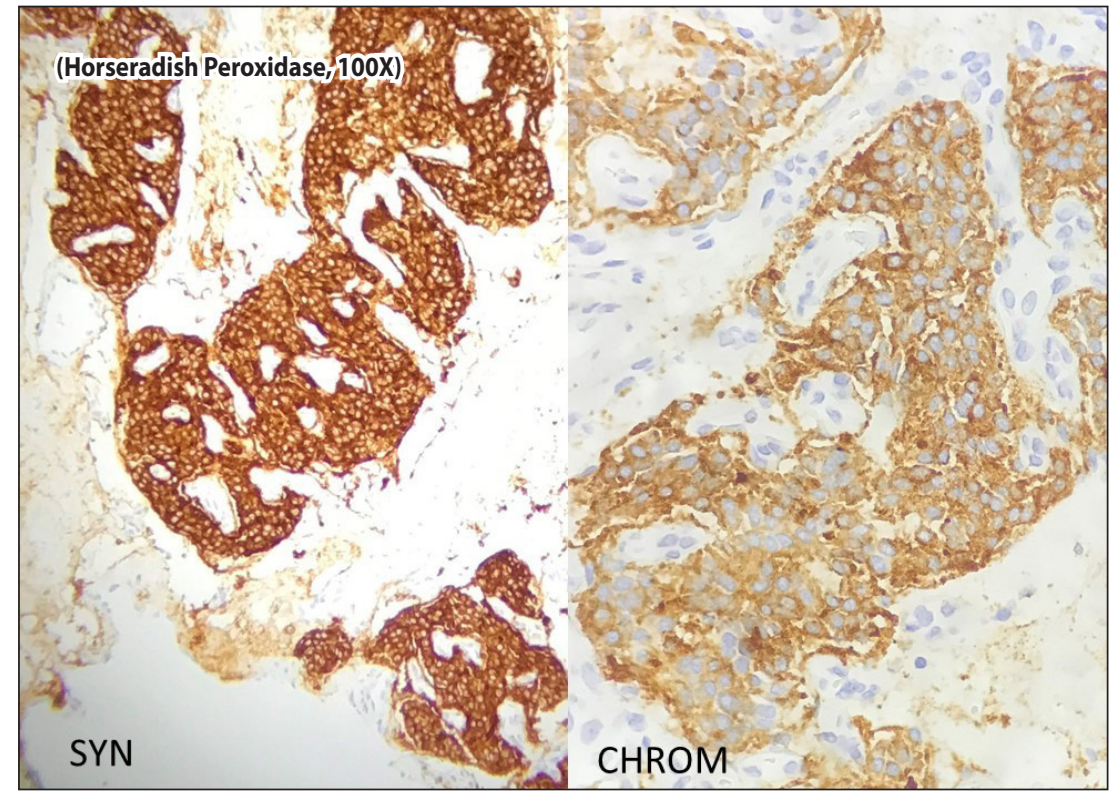

Figure 2. Diffuse cytoplasmic positivity on synaptophysin and chromogranin immunohistochemistry (Horseradish peroxidase method, $100 \mathrm{X}$ magnification).

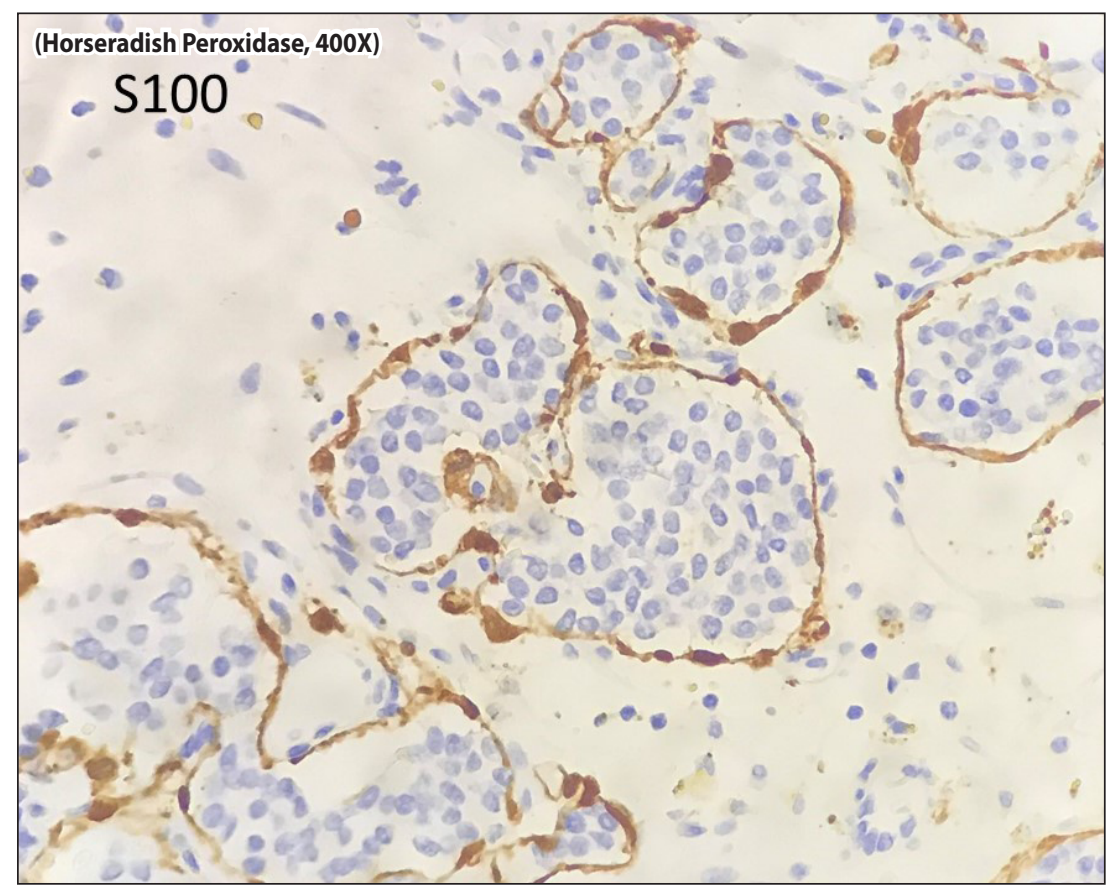

Figure 3. Peripheral positivity highlighting a layer of sustentacular cells around the cell clusters on S100 immunohistochemistry, (Horseradish peroxidase method, 400X magnification).
The morphology of paragangliomas in all head and necklocations is similar. Hematoxylin-eosin sections show cells arranged in organoid groups ("cell-ball", "Zellballen") surrounded by a vascular network. There are two cell types encountered: the chief cells which comprise the bulk of the cell nests and have abundant eosinophilic cytoplasm and the sustentacular cells which are spindly and located at the periphery of the nests. Neuroendocrine immunohistochemical stains (e.g. synaptophysin, chromogranin, CD56) highlight the chief cells while S100 and glial fibrillary acidic protein (GFAP) highlight the sustentacular cells. Cytokeratin is typically non-reactive and distinguishes this tumor from neuroendocrine tumors (i.e. carcinoid, neuroendocrine carcinoma) and middle ear adenoma. ${ }^{1,3}$ There are no consistent histologic features that can discriminate between benign and malignant cases, nor are there criteria that can predict aggressive behavior and metastasis. 1,2,3

Head and neck paragangliomas are slow-growing tumors and surgery is the most common treatment option. Radiotherapy is an option, especially for vagal paragangliomas where severe vagal nerve deficits occur in surgically treated cases. ${ }^{1}$ Recurrence after surgery is reported to be less than $10 \%$ for carotid and up to $17 \%$ in laryngeal cases. ${ }^{1}$ Metastasis on the other hand occur in $4-6 \%$ of carotid, $2 \%$ of middle ear and laryngeal, and $16 \%$ of vagal tumors. ${ }^{3}$ The World Health Organization nomenclature states that "all paragangliomas have some potential for metastasis (albeit variable)."1 Thus, long-term follow-up may be prudent for all cases.

\footnotetext{
REFERENCES

1. Kimura N, Capella C, Gill A, Lam AKY, Tischler AS, Williams MD. Paraganglion tumours. In: ElNaggar AK, Chan JKC, Grandis JR, Takata T, Slootweg PJ. World Health Organization Classification of Head and Neck Tumors. Lyon: IARC Press. 2017. P. 276-284.

2. Stelow EB, Mills SE. Biopsy interpretation of the upper aerodigestive tract and ear. $2^{\text {nd }}$ ed. Philadelphia: Lippincott Williams and Wilkins. 2013. P. 163-165.
}

3. Williams MD. Paragangliomas of the head and neck: an overview from diagnosis to genetics Head Neck Pathol. 2017 March 20. [Epub ahead of print] DOI: 10.1007/s12105-017-0803-4. PMID: 28321772. 